\title{
Are we making an impact?
}

\author{
Elizabeth Kay \\ Editor, EBD
}

\section{I} once heard it said that research is what we do when we don't know what we are doing. And, I suppose, to a large extent this is true. If we knew, without any doubt at all, the best treatment in every case; if we were certain what dosage of a drug would be effective; if we knew exactly how to make disease prevention work for all sectors of the community; if we could accurately predict people's behaviours; if we were absolutely clear why apparently reliable treatments fail sometimes, then we wouldn't need research. But we do not have the answers to these and many other questions, and so, hundreds and thousands of individuals dedicate their lives to exploring, sometimes in minuscule detail, every aspect of the mouth, it's health, it's diseases, and the routes to its(and therefore our) wellbeing. Every nuance, every intricate theory, every chemical and physiological pathway are dissected, analysed, synthesised, and processed into what? A research paper.

Is that sufficient, that the scientists achieve greater clarity each time they complete a piece of research? Is it enough that by publishing results, other researchers in the same field understand and view their own results in a new light? Is all that is needed to make a piece of research worthwhile that it is published and perhaps alters what the next researcher says about the subject? And does this increase in the knowledge of the scientific community justify the vast sums of money that support oral health research?

Surely it is only when new findings affect what is done in each and every dental practice and each home that the real value of research is realised? And that is why I, and the wonderful band of people who publish in EBD, who are all researchers in their own right, take the time to translate the details of other people's complex research into practical advice and actions that we can all take in order to try to benefit the population.

I once had the absolute pleasure of addressing a research symposium at the
International Association for Dental Research annual conference, at which I conducted a straw poll among the researchers in the audience. I asked them why they did what they did. I asked them what motivated them, what got them out of bed in the morning to go to their labs and their computers and their microscopes. And the answers were 'to make a difference', 'to make things better', 'to change people's lives'. These were top researchers, people conducting truly groundbreaking research. And yet, it seemed, they did not research in order to make money, nor to enhance their careers, or grow their reputations. They undertake work which, let's face it, is unbelievably difficult, particularly in dentistry. Because being a researcher means continually chasing money and grants, writing endless proposals, arguing their case with increasingly onerous ethics committees, continually and systematically collecting data which then must be rigorously and painstakingly analysed before being condensed into a publishable paper which has to be agreed by every author before publication. Research is not easy or simple, and the pressure that researchers are under to produce more and more work of greater and greater complexity is immense. And it's not particularly well paid, either! Yet people do it. And keep doing it. They told me that they keep doing what they do because they want to leave the world (in this case, the world of dentistry and oral health) a better place than when they came into it.

Here is the problem. In order to have some way of measuring whether researchers are doing what they are supposed to be doing, their "owners",their bosses and employers need a metric to assess the quality of the research being produced. The metric used, by both universities and our government, is the impact factor.

Now, the dictionary definition of 'impact' is 'to have a strong effect on something or someone' (which is exactly what the researchers told me they wanted to do. Indeed it was the reason they had chosen their research career). So impact factors must be a useful measure to have? Well I would disagree with that, because impact factor is actually a measure of how many other researchers in a particular field read a given journal. So it becomes a selffulfilling tautology. Your research is good if you publish it in a journal with a high impact factor, and high impact factor publications mean the research is good! But surely if researchers actually research in order to make a difference to people and society through their work, it is desperately important that it is read, and acted on by people other than fellow academics. It needs to be read, and appreciated by those who look after people, patients and populations. It need to be understood, consolidated into action, and practised by those at the front line of care. That is the aim of each edition of Evidence Based Dentistry, to ensure that the potentially hugely valuable and valued work, done by the world's best dental researchers is made accessible and elucidated, and wherever possible, translated into real actions that practitioners and policy makers can take. And those actions, that turning of research results into practice, means that research will 'make a difference' - which is what not only researchers, but everyone in dentistry, wants to do. Then we have a win -win. Or even better the researchers get what they desire, practitioners make a difference to their patients, and patients benefit. A winwin-win in fact!

So I end by giving my heartfelt thanks and admiration to the excellent people who write for this journal. The contributors are people who have the expertise to understand and critically research, and also the skill to interpret, make it digestible, while at the same time emphasising why it is important to patients and practitioners. To be able to do both these things requires a rare combination of talents which, I for one, am immensely grateful. 